\title{
Function of the nucleus accumbens within the context of the larger striatal system
}

\author{
SHERI J. Y. MIZUMORI, WAYNE E. PRATT, and KAY E. RAGOZZINO \\ University of Utah, Salt Lake City, Utah
}

\begin{abstract}
There is accumulating evidence that the nucleus accumbens plays an important role in spatial navigation, and it has been suggested that the accumbens functions to integrate spatial and reward information to affect behavioral performance (e.g., Lavoie \& Mizumori, 1994). Here, a hypothesis is proposed that more specifically takes into consideration the nature of the contribution of the accumbens. Specifically, it is argued that the accumbens operates in conjunction with the caudate-putamen to provide organisms with a response reference system whereby the success of current behavioral strategies can be evaluated. The accumbens is postulated to carry out this function with respect to current changes in the sensory (spatial) environment, whereas the caudate-putamen evaluates the effectiveness of current responses, relative to response efficacy predicted by past experience. The striatum as a whole, then, endows the navigation system with a response-based mechanism by which memory representations and current environmental information (from the neocortex) can guide future spatial behaviors.
\end{abstract}

Our understanding of the neurobiology of spatial navigation has been maturing at a rapid rate in recent years (see, e.g., Burgess, Recce, \& O'Keefe, 1994; Eichenbaum, 1996; McNaughton et al., 1996; Mizumori, 1994; Mizumori, Lavoie, \& Kalyani, 1996; Muller, Stead, \& Pach, 1996; Poucet \& Benhamou, 1997; Sharp, Blair, \& Brown, 1996; Taube, Goodridge, Golob, Dudchenko, \& Stackman, 1996; Wiener, 1996). Neurophysiological investigations typically focus on the role of hippocampal place cells and head direction cells of the limbic thalamus and neocortex. Place cells are those that selectively discharge when animals traverse discrete areas of an environment. Head direction cells preferentially discharge when animals orient their head along certain (horizontal) trajectories in space and not along others. Both cell types appear to rely on the integration of visual and self-motion information, although the relative dependence on these inputs may vary. Full appreciation of the limbic contribution to spatial learning cannot be achieved unless one also understands how limbic information is used to guide an animal's behavior. To this end, Lavoie and Mizumori (1994) and, more recently, many others (e.g., Kawagoe, Takikawa, \& Hikosaka, 1998a; Redish \& Touretzky, 1997; Sharp et al., 1996) have argued that at least the nucleus accumbens portion of the striatum may integrate limbic spatial information with reinforcement consequences to regulate navigational behavior. Such a claim is consistent with a currently held view that the nu-

This work was supported by NSF Grant IBN 9514880 and NIH Grant MH58755 to S.J.Y.M. and by NSF Grant DGE9616182 to K.E.R. We thank James Canfield, Brent Cooper, and Stefan Leutgeb for comments on earlier versions of this manuscript. Correspondence concerning this article should be addressed to S. J. Y. Mizumori, Department of Psychology. 390 S. 1530 E., Rm. 502, University of Utah, Salt Lake City, UT 84112-0251 (e-mail: mizumori@behsci.utah.edu). cleus accumbens is involved in the acquisition of new spatial information.

Below, we briefly summarize evidence suggesting a spatial contribution by the nucleus accumbens and then propose that the accumbens and the dorsal striatum (caudateputamen in rats) may function in coordination to modify the future selection of adaptive behaviors. The coordination is hypothesized to reflect the operation of a response reference system whereby the expected reinforcement outcome associated with a particular cognitive/behavioral strategy is compared with that currently being experienced. Within this common functional domain, the accumbens and the caudate-putamen may make individual contributions. The accumbens may be preferentially involved in the initial (acquisition of) reward-space associations, such as that which occurs when animals enter new environments. By comparison, the caudate-putamen is more directly influenced by past memories, thereby allowing for a mechanism by which animals can evaluate the extent to which previously effective behavioral patterns remain appropriate. Both accumbens and caudate-putamen outputs eventually inform neocortical selection of specific response options.

\section{A Role for the Nucleus Accumbens in Spatial Learning}

Disruption of nucleus accumbens function seems to have selective effects on learning and memory. Pretraining interventions produce significant impairments in a variety of spatial tasks (see, e.g., Annett, McGregor, \& Robbins, 1989; Floresco, Seamans, \& Phillips, 1996a, 1996b; Gal, Joel, Gusak, Feldon, \& Weiner, 1997; Ploeger, Spruijt, \& Cools, 1994; Seamans \& Phillips, 1994; Sutherland \& Rodriguez, 1989). Many of these same studies also demonstrate that the accumbens does not impair learning of nonspatial variants of the same tasks. Furthermore, 
posttraining compromise of the functioning of the accumbens produces transient or no impairment of the spatial function. These latter conditions are important to note, since the accumbens is well known for its role in motivation (Robbins \& Everitt, 1996) and motor activity (Mogenson \& Yang, 1991). Thus, analogous to what has been shown for the hippocampus (e.g., Kim \& Fanselow, 1992; Morris, Garrud, Rawlins, \& O'Keefe, 1982; Olton, Walker, \& Gage, 1978; Scoville \& Milner, 1957; ZolaMorgan \& Squire, 1990), the nucleus accumbens appears to be importantly involved in the acquisition of new spatial information.

In addition to the studies suggesting a possible role for the accumbens in spatial learning, there are other reports describing failures to find spatial deficits following accumbens lesions. For example, Floresco et al. (1996a) showed that lidocaine-induced inactivation of the accumbens prior to training resulted in no impairment in the learning of a spatial variant of the water maze task. One explanation for this discrepancy in the literature is that the Floresco et al. (1996a) study targeted the shell subregion of the accumbens, whereas other studies (e.g., Ploeger et al., 1994) targeted not only the shell but also the core subarea. It has been suggested that the core and shell regions subserve different behavioral systems (e.g., Maldonado-Irizarry \& Kelley, 1995; Weiner, Gal, Rawlins, \& Feldon, 1996).

The similarities between the spatial behavioral consequences of nucleus accumbens lesions and those of hippocampal lesions (O'Keefe \& Nadel, 1978) suggest that these two structures are part of the same functional system. The following question then arises: Are there unique contributions of each structure? Before this question can be answered in full, it is argued below that it would be prudent to consider the possibility that the accumbens is part of a larger striatal functional system that is important for adaptive spatial behaviors.

\section{The Nucleus Accumbens Within a Larger Striatal System}

Results from many levels of analysis indicate that the accumbens should be considered to be functionally related to the caudate-putamen complex (dorsal striatum in rats). In terms of behavioral evidence, similar spatial acquisition deficits were observed following medial caudate-putamen or accumbens lesions when rats were trained according to place-learning paradigms in water mazes (Devan \& White, 1997; Furtado \& Mazurek, 1996; Whishaw, Mittleman, Bunch, \& Dunnett, 1987) or radial mazes (see, e.g., Colombo, Davis, \& Volpe, 1989). Caudate-putamen-lesioned rats were also impaired on a spatial reversal task in which the rats learned to select goal arms not selected during initial (pre)training (Mitchell, Channell, \& Hall, 1985). It was proposed that one explanation for the spatial deficit is a disruption of the underlying mechanisms of response-reinforcer associations, since lesioned rats did not show the normal overshadowing effect that one expects to observe when response- reinforcement training follows stimulus-reinforcement training. It would be of interest to determine whether nucleus accumbens lesions produce similar overshadowing deficits.

The Mitchell et al. (1985) study illustrates a current enigma regarding the contribution of the caudate-putamen to learning. That is, in apparent contrast with the evidence that the caudate-putamen is involved in spatial processing, other studies not only suggest a preferential role of the caudate-putamen in stimulus-response or egocentric learning, but also show no deficits in spatial learning. Cook and Kesner (1988) and Kesner, Bolland, and Dakis (1993) reported that caudate-lesioned rats were impaired in their ability to learn to turn in a particular direction from a start location. White and colleagues (McDonald \& White, 1993; Packard, Hirsh, \& White, 1989) found that caudate-putamen lesions impaired rats' ability to associate a particular response with the presentation of a light cue on a radial maze. More recently, Packard and McGaugh (1996) showed that reversible caudate-putamen inactivation reduced response strategy use by rats trained on a T-maze. Finally, Knowlton, Mangels, and Squire (1996) described Parkinson's patients who were impaired on a stimulus-response type of task in which a fixed set of stimuli were probabilistically related to one of two responses. These same studies provide evidence (by producing double and triple dissociation effects) that the caudate-putamen is not important for context-dependent (spatial) learning.

On comparing the lesion sites that produced spatial- or response-learning deficits, it can be seen that lesions of the dorsolateral sector of the caudate-putamen produced response-learning deficits, whereas ventromedial lesions produced the spatial deficits that are similar to those observed following nucleus accumbens lesions. It is worth noting, however, that the above studies did not systematically compare the dorsolateral caudate-putamen, the ventromedial caudate-putamen, and the nucleus accumbens in the same study, much less in the same behavioral task. One study that did provide this important comparison found that lesions of the accumbens and of the ventromedial caudate-putamen abolished a sucrosebased conditioned place preference in rats (Everitt, Morris, O'Brien, \& Robbins, 1991). Dorsolateral caudate-putamen lesions had no effect. The finding by McDonald and White (1994) complement those of the Everitt et al. study in that dorsolateral caudate-putamen lesions enhanced the control that spatial cues had on navigation. It appears, then, that the behavioral evidence supports the view that the ventromedial caudate-putamen and the accumbens operate within a similar functional system and that this may be somewhat distinct from that of the dorsolateral caudate-putamen.

The effect of discrete striatal lesions on different forms of learning is consistent with known regional variability in anatomical connections and neurochemical compartments. The ventromedial portion of the caudate-putamen is more similar to the nucleus accumbens than to the dorso- 
lateral aspect of caudate-putamen in many respects. The border between the ventral caudate-putamen and the accumbens is rather indistinct. Both areas receive mesocortical, allocortical, amygdaloid, and ventral tegmental input (Beckstead, Domesick, \& Nauta, 1979; Kelley \& Domesick, 1982; McGeorge \& Faull, 1989). At a cellular level, the primary output neuron of each area is the medium spiny neuron, which sends a main efferent to the pallidum and which also give rise to locally distributed collaterals that remain in the vicinity of the cell body (Kawaguchi, Wilson, \& Emson, 1990; Kitai, Preston, Bishop, \& Koscis, 1979). Histochemically, it has been shown that large aspiny neurons dispersed among the medium spiny output neurons serve as cholinergic interneurons (Butcher \& Woolf, 1984). Similarities in terms of extrinsic and intrinsic connection patterns have suggested to some that it may be futile to functionally distinguish, especially, the ventromedial caudate-putamen and the nucleus accumbens (e.g., Gerfen, 1992; Heimer, Zahm, \& Alheid, 1995).

The main anatomical distinction of the dorsolateral caudate-putamen is that, unlike the ventromedial caudateputamen and the nucleus accumbens, there is somatotopically organized input from the primary motor and primary somatosensory cortex, with preferential (but not exclusive) termination in the dorsolateral caudate-putamen (Flaherty \& Graybiel, 1993; Kemp \& Powell, 1970). Neurophysiological recordings have verified this functionally by revealing topographically organized sensorimotor cellular responses, primarily in the dorsolateral caudateputamen (Cho \& West, 1997).

Recordings from neurons of the nucleus accumbens and the caudate-putamen in freely navigating rats further support the notion of functional overlap between these two striatal regions. Both areas appear to be sensitive to reinforcement, spatial aspects of navigation-related be- haviors, and specific movement elicited by the animal (Lavoie \& Mizumori, 1994; Mizumori \& Cooper, 1995; Mizumori, Ragozzino, \& Cooper, 1999; Mizumori, Ragozzino, Leutgeb, \& Cooper, 1998; Mizumori, Unick, \& Cooper, 1996). Reinforcement-related neural representations are manifested by significant modulation of firing rates during encounters of rewards, as well as by apparent "expectation" of reward encounters in both the accumbens and the caudate-putamen (see Figure 1 for examples). Moreover, both caudate-putamen and accumbens neurons discriminate rewards of different magnitudes. With specific regard to the nucleus accumbens, evidence was also found to suggest that integration of reward and spatial information occurred at the single cell level, since some units showed reward sensitivity, but only at certain locations on the maze. Although evidence for such rewardlocation integration has not yet been observed in the rat caudate-putamen, such integration was recently proposed for the monkey caudate nucleus (Kawagoe, Takikawa, \& Hikosaka, 1998b).

The rodent results presented above are consistent with the primate neurophysiological literature, which suggests that striatal neurons are engaged in processing information about learned events (e.g., presentation of a reward); their discharge seems to be evoked by the "expectation" of such events (see, e.g., Apicella, Legallet, \& Trouche, 1997). Factors that contribute to the (neural) expectation response include not only whether an event is going to occur, but also the location of the event or target stimulus (Hikosaka, Sakamoto, \& Usui, 1989), as well as the direction of impending behavioral acts (Alexander \& Crutcher, 1990). Recently, Kawagoe et al. (1998a) showed that the directional preferences of striatal cells vary, depending on the reward context. These data are consistent with earlier reports that striatal unit firing depends more on the context in which actions occur than on the spe-
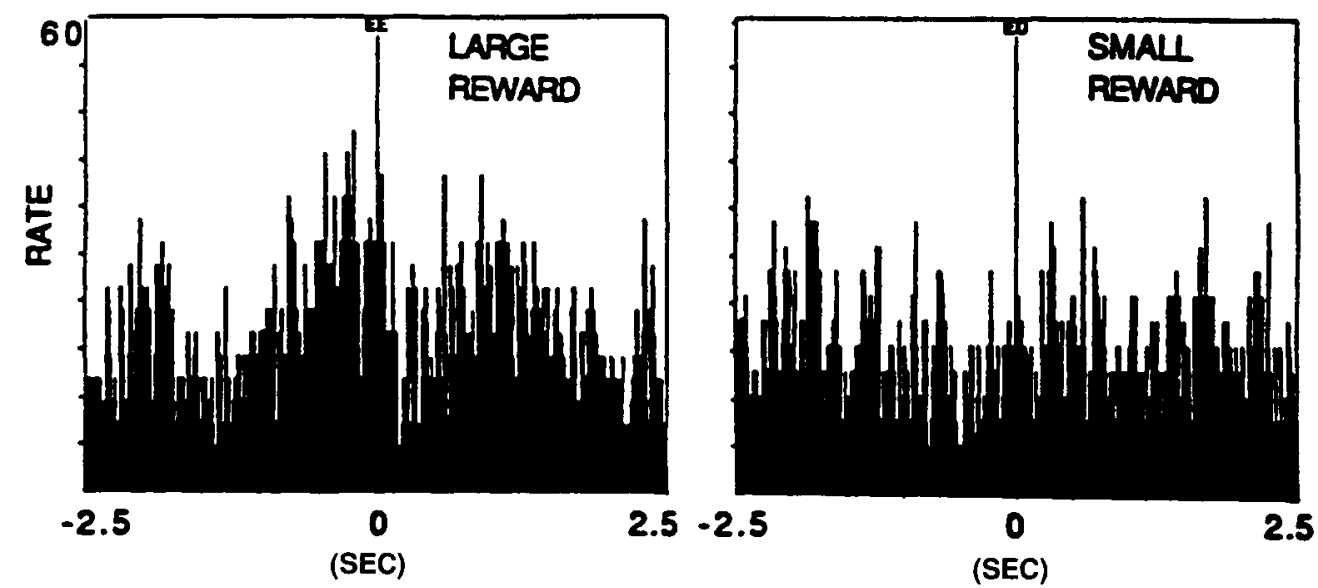

Figure 1. Illustration of changes in firing rate by a caudate-putamen cell as a function of encounters with large or small amounts of reward, which were found at the ends of alternating maze arms $\left(T_{0}=\right.$ the time at which the animal reached the ends of the maze arm). This cell showed a significant increase in firing prior to encounters of large reward, but not of small rewards. 
cific response of the animal (e.g., Gardiner \& Kitai, 1992; Kimura, 1990; Rolls, 1994; Rolls, Thorpe, \& Maddison, 1983; Schultz \& Romo, 1992).

A second behavioral correlate common to the nucleus accumbens and the caudate-putamen of rats during navigational activity is localized discharge that resembles the place fields recorded from hippocampal neurons (O'Keefe \& Dostrovsky, 1971). That is, many striatal neurons selectively fire when rats move in particular directions through restricted portions of the maze environment (Figure 2). Also, similar to hippocampal place fields, striatal place fields appear to be visually dependent, in that they show dramatic changes in their characteristics when animals perform tasks in darkness. A noticeable difference, however, between hippocampal and striatal place fields is that the striatal fields tend to be more broad, often extending over multiple arms of a radial maze. Although possible, it is unusual to find a striatal place field that is restricted to a single maze arm. The latter pattern is more typical for hippocampal place fields, when recorded from rats tested according to the same behavioral paradigm, although broad hippocampal place fields are also found (e.g., Mizumori, McNaughton, Barnes, \& Fox, 1989). The comparatively low spatial selectivity by striatal place cells may reflect the fact that striatal spatial codes also include nonspatial context-relevant information. Despite differences in spatial selectivity, striatal place fields are as reliable as hippocampal fields.

A third behavioral correlate common to the caudateputamen and the nucleus accumbens is sensitivity to specific movements made by the animal. That is, cells selectively increase or decrease discharge during behavioral acts such as making $180^{\circ}$ turns at the ends of maze arms or during forward translational movements (Figure 3). Many of these movement-sensitive neurons also discriminate movements in different directions, such as right turns from left turns or forward movement in one direction from similar movements in other directions. None of these movement correlates appears to be sensitive to changes in the visual spatial environment. It is worth noting that, at this time, it is unclear whether the above unit-behavioral correlates are characteristic of the entire extent of the caudate-putamen, since in our initial studies, there was a bias toward recording mostly from the ventromedial caudate-putamen.

The striking similarities between the nucleus accumbens and a significant portion of the caudate-putamen in terms of behavioral dependence and anatomical definition of extrinsic and intrinsic connections, as well as the neurobehavioral correlates of single unit activity, provide strong evidence that at least the ventromedial caudateputamen and the nucleus accumbens operate within a single functional system.

\section{The Striatum as a Response Reference System}

Rolls (1994) and Wise, Murray, and Gerfen (1996) have recently proposed that the striatum can perform both stimulus-response learning and context-dependent learning by selectively employing two distinct patterns of cortical inputs. One afferent pattern includes the somatotopically organized motor and somatosensory inputs (Cho \& West, 1997; Flaherty \& Graybiel, 1993; Kemp $\&$ Powell, 1970). Other sensory afferents are also topographically organized, with visual and auditory input being predominant in the ventromedial caudate-putamen and the accumbens. Activation of these somatotopic sensory afferents may initiate striatal involvement in stimulusresponse learning.

A second afferent pattern is one in which spatially diverse but functionally related areas of the association cortex converge onto restricted zones of the striatal infrastructure. Wise et al. (1996) and Rolls (1994) suggest that the convergent pattern of striatal activation supports context-dependent learning. The suggestion that the topographic sensory and motor afferent pattern mediates the less flexible response learning, whereas the convergent pattern mediates the flexible processing characteristic of context-dependent learning, is entirely consistent with what has been suggested by Merzenich and colleagues in regard to neocortical plasticity (e.g., Merzenich \& DeCharms, 1996). In situations in which there are more topographically constrained patterns of anatomical connectivity, a limitation is placed on the combinatorial results that are possible, and well-defined sensory-response relationships might predominate. By comparison, the combinatorial power of convergent systems is extensive, endowing the system with the high degree of flexible processing necessary for unique integration of a vast array of (sensory, motor, reward, and other associational) information.

Although response learning and more flexible cognitive processing may utilize different striatal afferent systems, it is possible that the different afferent systems implement similar intrastriatal computational functions. Both sensory and association types of inputs are thought to innervate GABAergic, medium spiny projection neurons that are found throughout the striatum. These cells have a unique membrane property in which the bistable membrane potential can exist in up or down states. The down state is caused by a massive inwardly rectifying potassium current that serves as a shunt for weak or nonsynchronous inputs. Transition between states is regulated by the temporal and spatial pattern of excitatory afferents, and not by local synaptic inhibition (Wilson, 1995). Temporally coherent cortical afferents synchronize the onset of the up states across neuron ensembles (Stern, Jaeger, \& Wilson, 1998). Dopamine signals concerning reinforcement conditions (presumably from the substantia nigra and the ventral tegmental area) may then serve to modulate the synaptic efficiency of medium spiny neurons with repeated experience (Houk, 1995; Schultz, Apicella, Romo, \& Scarnati, 1995). Such similarities in the intrinsic organization of the accumbens and the caudateputamen (both dorsolateral and ventromedial segments) suggest that they may be part of the same computational system. 

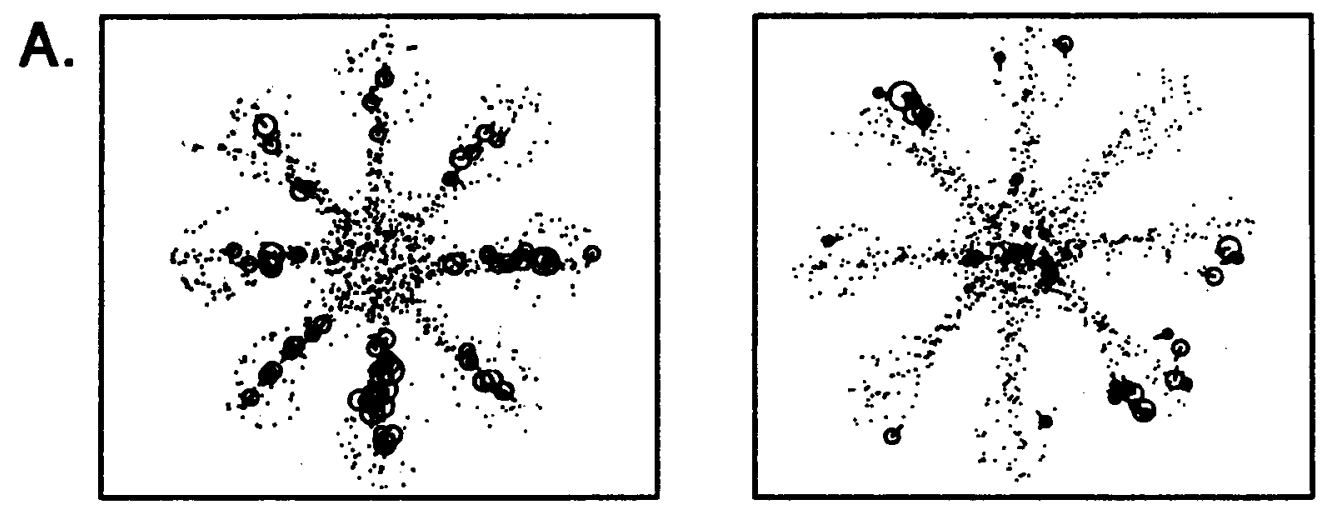

$T_{0}=$ BEGINNING OF TURNS IN FIELD

$T_{0}=$ BEGINNING OF TURNS OUT OF FIELD
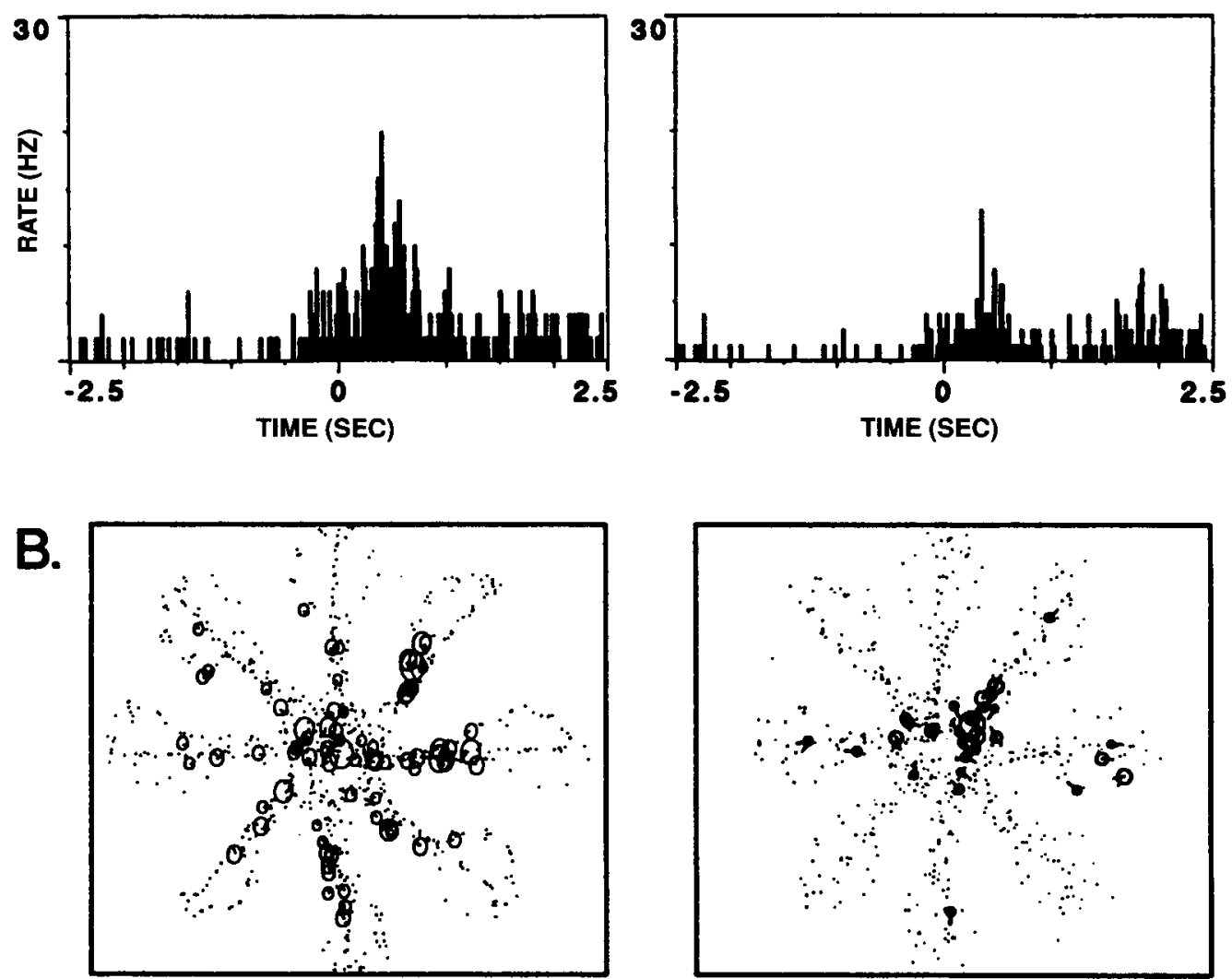

Figure 2. Examples of the spatial distribution of firing by accumbens neurons $(A)$ and caudate-putamen neurons (B). A comparison of the left and the right spatial plots in panel $A$ illustrates the range of spatial selectivity observed for accumbens place neurons, from broadly turned place cells (left) to location-specific place cells (right). Dots indicate locations on the maze that were visited by the rat. The size of the circles is proportional to the local firing rate of the cell, and vectors indicate the direction of movement through the field. Note that even the broadly tuned place cells showed directional specificity - in this case, in the outward direction. The place cell on the right revealed its location sensitivity when animals made $180^{\circ}$ turns at the ends of the $\mathrm{NW}, \mathrm{SE}$, and $\mathrm{E}$ maze arms. This is shown more clearly by the accompanying peri-event histograms: The left histogram shows that peak firing occurred during turns made within the place field, and not during turns made out of the place fields. Similar to accumbens place cells, caudate-putamen place cells (B) exhibited a range of spatial selectivity, from broad (left) to specific (right). Broadly tuned caudateputamen place cells showed clear directional selectivity: This cell fired almost exclusively when the rat moved in the inward direction. 
A.
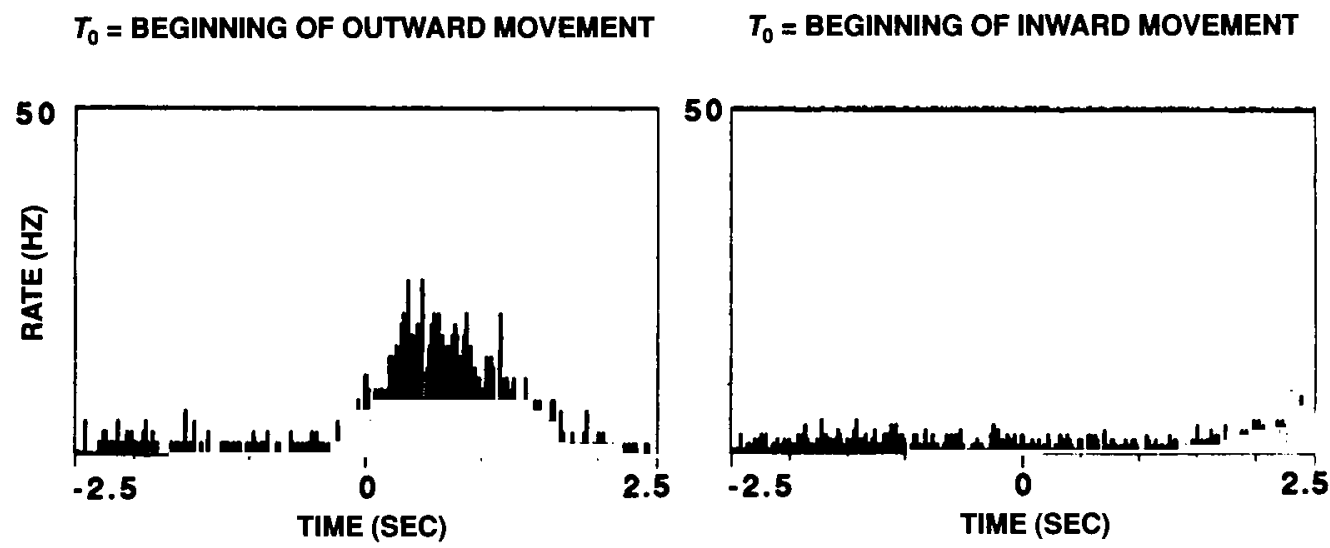

B.
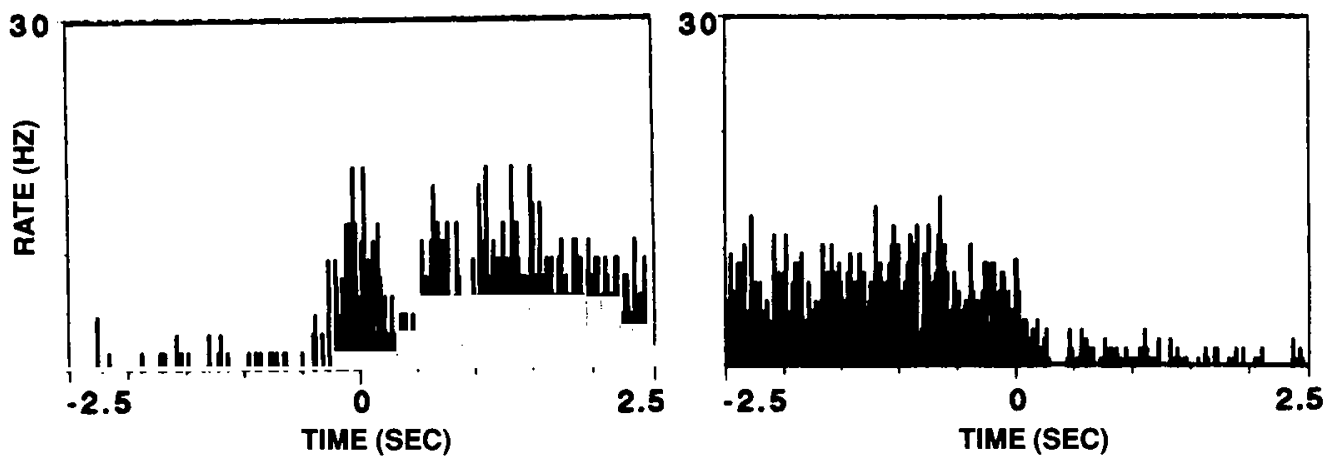

C.
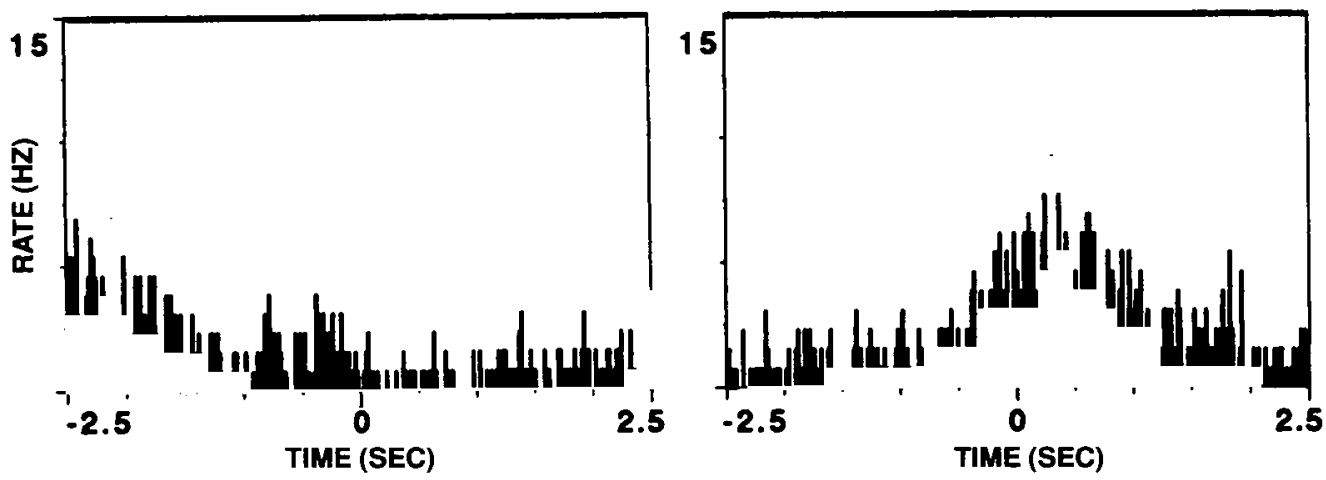

Figure 3. Three examples of movement sensitivity by striatal neurons. $T_{0}$ is indicated in the figure. (A) This nucleus accumbens neuron showed elevated discharge when the animal made forward translational movements. Moreover, it can be seen that the movement correlate was specific to times at which the rat moved in the outward direction on maze arms. This indicates that the movement cell was not merely reflecting behavioral activation per se. (B) In contrast to the cell shown in panel $A$, a different accumbens neuron rarely fired during forward translational movement, but rather increased discharge just prior to stopping at the arm ends.(left panel). This elevated discharge pattern was maintained until the rat started a $180^{\circ}$ turn to return to the central platform of the maze (right panel). (C) Caudate-putamen cells show patterns of movement sensitivity that are similar to those of accumbens cells. This cell was recorded from the caudate-putamen, and it selectively fired during inward, forward movements. For all cells, bin width is 10 msec. 
Our current working hypothesis regarding the striatal contribution to spatial learning in particular is that the striatum refines the selection of future action patterns that are deemed appropriate for the current sensory environment. Both the accumbens and the caudate-putamen accomplish this via the initial convergence of afferent cortical information, their own intrinsic processing system, and the reconvergence of striatally processed information in the pallidum that ultimately updates frontal and parietal/temporal memory (i.e., context-based) representational systems. Association regions of the mesocortex and the allocortex provide the striatum with information concerning the sensory, motor, and reinforcement definition of the expected context, as well as information concerning the immediate sensory surround and the current behavioral state. (It is likely that the frontal cortex also receives similar contextual information, enabling it to provide the striatum with information regarding response strategy options appropriate for a specific situation.) By integrating these kinds of cortical information with dopaminergic input, the striatum is able to evaluate the reinforcing consequences of (1) current egocentric behaviors (e.g., turns, translational movement, etc.), (2) temporally contiguous environmental stimuli and responses, (3) spatial dimensions of an expected sensory environment (e.g., locations), and (4) behaviors guided by the spatial attributes of an expected environment (e.g., experience-dependent heading direction).

In accordance with our hypothesis, a primary functional goal of the striatum is to indicate to the frontal cortex the effectiveness of the current response strategy option. This may be accomplished with the aid of dopamine, which ultimately reinforces synaptic weights within cortical association areas. Depending on the area affected, such input could reinforce the continued use of a behavioral strategy and/or guide the updating, or consolidation, process. Since reinforcement guides learning, the neural pattern that is eventually learned should reflect the most recent update of a behaviorally relevant context. We view this specific contribution of the striatum to learning as providing the organism with a response reference system whereby comparisons are made between the expected success of learned behavioral strategies and the consequences of behaviors currently being expressed. This is a function that can be generally useful for many forms of learning.

If the response reference system is generally useful, why is it that selective behavioral deficits are observed, depending on the lesion site within either the accumbens or the caudate-putamen? As was argued by Rolls (1994) and Wise et al. (1996), different learning situations activate different patterns of striatal afferents. Since the striatal afferents are topographically organized, the lesion site critically determines the nature of the behavioral deficit.

It is likely that response learning and spatial learning use at least some common attributes of the response reference system. Response learning requires an association to be made between a well-defined motor act, or a current external stimulus, and its immediate consequence. Thus, the dorsolateral striatum is optimally situated to provide response selection systems of the neocortex with feedback concerning the consequences of the behavioral strategy currently being employed. However, response flexibility is not required and may, in fact, be detrimental to good performance. Therefore, the most direct way by which learning can take place is to use the striatal somatotopic afferent circuit. As a result, behavior is relatively inflexible, habitual in appearance (because the response can be elicited with short latency), and acquired slowly.

More complex contextual learning (e.g., spatial learning), on the other hand, is not based on learning explicit stimulus-response relationships. Rather, out of necessity, spatial learning activates neural circuits that allow for flexible processing of sensory and response information: The hippocampal sensory-based, or spatial, reference system may ultimately allow animals to organize sensory information in different ways, whereas the striatal response reference system helps animals to flexibly consider different response options in a given environment. When both systems operate together, perturbations in the sensory environment or available response options can be readily accommodated, leading to adaptive behavioral change.

To return to the issue concerning the difference in contextual processing by the striatum and the hippocampus, we propose that the key difference is that the striatum places contextual information it receives from cortical association areas (which includes the sensory qualities of the environment, as well as the response parameters and reinforcement contingencies within that environment) within the framework of motor instructions, whereas the hippocampus places perhaps similar contextual information within a learned sensory coordinate system. In other words, the striatum and the hippocampus place contextual information within different coordinate systems, which, by virtue of their distinct patterns of efferent, afferent, and intrinsic connections, are either response based (striatum) or sensory based (hippocampus). This distinction between motor and sensory coordinate systems for processing incoming sensory input is not without precedent. A somewhat counterintuitive view of spatial perception is emerging, which argues that information codes in the parietal and frontal cortex are action based (e.g., Colby \& Duhamel, 1996; Fogassi et al., 1992; Gross \& Graziano, 1995). According to this view, incoming sensory information is multiply represented in terms of the possible actions that can be performed in, say, a particular place. Neurophysiological evidence indeed shows that numerous sensory-dependent behavioral correlates of cortical neurons occur within some form of organism-centered coordinate system-for example, head centered (Colby \& Duhamel, 1991), body centered (Gentilucci, Scandolara, Pigarev, \& Rizzolatti, 1983), or center of gaze (Duhamel, Colby, \& Goldberg, 1992). 
Are There Unique Contributions of the Accumbens and the Caudate-Putamen to Spatial Learning?

It is likely that the numerous similarities in intrinsic organization, as well as interconnections with afferent and efferent structures, by the caudate-putamen and the accumbens reflect the fact that both are part of a related functional system, perhaps a response reference system. Within the functional domain of such a system, the caudate-putamen and accumbens may, however, still make distinct contributions to spatial learning. Such a characterization seems warranted, given that, in addition to similarities, there are significant differences between the caudate-putamen and the accumbens. First of all, there appears to be no clear relationship between patches found in the accumbens and those found in the caudate-putamen. For example, although enkephalin patches in the caudomedial shell region of the accumbens appear similar to caudate-putamen patches in terms of afferent connections, enkephalin patches in the rostral and lateral shell region appear more similar to the caudate-putamen matrix (Jongen-Relo, Groenewegen, \& Voorn, 1993). Thus, a comparable relationship between cell clusters and enkephalin patches in the accumbens and the caudate-putamen is not observed, suggesting a difference in the intrinsic neurocomputations that are performed.

A second difference refers to neurophysiological investigations of the accumbens and the caudate-putamen: Head direction cells have been observed in the ventromedial caudate-putamen (Mizumori \& Cooper, 1995; Mizumori et al., 1998; Mizumori, Unick, \& Cooper, 1996; Wiener, 1993), but such cells have not been observed in the nucleus accumbens (Lavoie \& Mizumori, 1994). The selective presence of head direction cells in conjunction with place cells (Mizumori et al., 1998; Ragozzino \& Mizumori, 1998) suggests that the caudate-putamen may calibrate an organism's behavioral patterns to the external (visual) environment. In fact, it has been suggested that the caudate-putamen integrates visual (spatial) feedback to guide and improve the accuracy of movements (Mitchell \& Hall, 1988). Alternatively, caudate-putamen integration of visual spatial movement may improve the accuracy with which behaviors are monitored.

A third distinction between the accumbens and the caudate-putamen concerns the source of their limbic cortical input (McGeorge \& Faull, 1989). For the ventromedial caudate-putamen, the input is more mesocortical
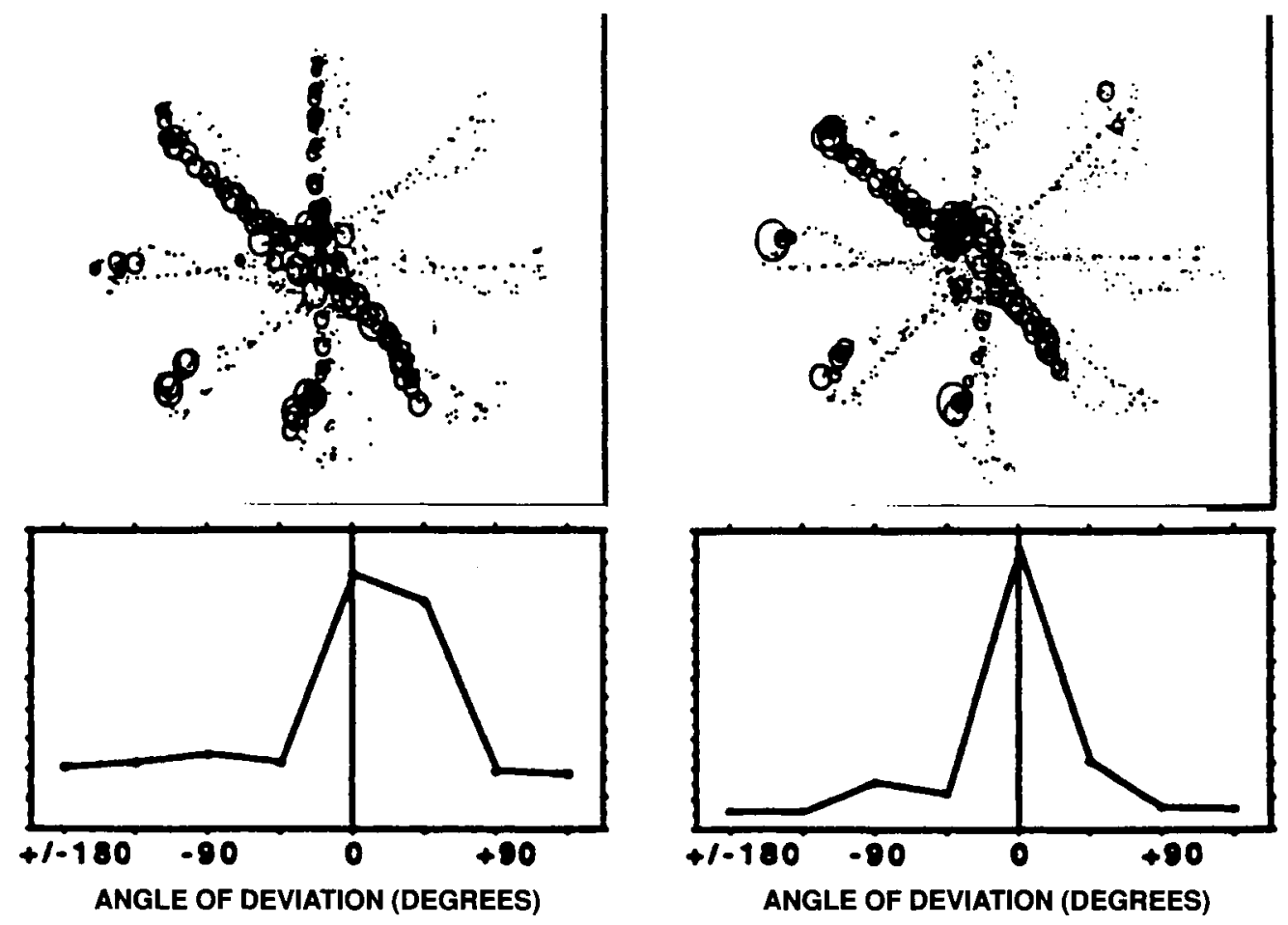

Figure 4. Two examples of head direction cells recorded from the ventromedial portion of the caudateputamen. About half of the head direction cells recorded showed preferential firing in two of the possible eight directions, whereas the other half of cells exhibited more selective head direction biases toward a single direction. The cell on the left preferred the $\mathrm{N}$ and $\mathrm{NW}$ directions, and the cell on the right preferred just the NW direction. Tuning curves (bottom) illustrate the firing rates of these cells as a function of angle of deviation from the direction associated with the highest firing rate. Maximum rates for left and right tuning curves are 35 and $60 \mathrm{~Hz}$, respectively. 
in nature than allocortical, emphasizing retrosplenial and entorhinal influences. In contrast, the nucleus accumbens receives its limbic cortical input more from allocortical regions (e.g., the ventral subiculum) than from mesocortical areas. The functional consequences of the differing limbic cortical inputs may not be trivial. Rather, it may determine the differential contributions of the ventromedial caudate-putamen and the nucleus accumbens to adaptive navigation. The nucleus accumbens may be in a more optimal, strategic position to specialize in processing new spatial information because it has rather direct and immediate access to a primary hippocampal output structure (the subiculum), and hippocampal output is hypothesized to reflect the most current evaluation of changes in spatial contextual information relevant to new learning (see above). The nucleus accumbens may, then, have the specific role of associating ongoing behavioral strategies/responses and their consequences with changes in perception of the current spatial context.

The ventromedial caudate-putamen, on the other hand, by virtue of its innervation by mesocortical structures, may be more directly influenced by past memories of (i.e., expected) behaviorally relevant contextual information than by the most current evaluation of change in spatial environment. As such, this region may evaluate the extent to which previously determined effective behavioral patterns remain effective and appropriate. In this way, the caudate-putamen not only can inform and update neocortical selection of response options (Wise et al., 1996), but also can update cortical memory representations of the expected reinforcement and response significance of a particular spatial context. Together, the accumbens and the caudate-putamen regions of the basal ganglia evaluate the success of current behavioral strategies, thereby endowing the navigation system with a response-based mechanism by which memory representations (from the neocortex) can guide future spatial behaviors.

\section{Future Directions}

To evaluate the hypothesized distinction between the nucleus accumbens and the caudate-putamen components of the striatum, it is important that experiments begin to employ within-subjects designs as much as possible. Furthermore, both brain areas should be assessed as animals perform the same behavioral task. One way to accomplish this is to compare the behavioral consequences of reversible inactivation of either the accumbens or the caudate-putamen in the same animal performing a single task. Reversible inactivation is preferred over permanent lesions in this case because it allows within-subjects comparisons. In addition, the close (anatomical and functional) relationship between these structures makes it quite possible that functional compensation occurs in one when the other is permanently damaged.

One prediction of the response reference interpretation of the striatum's contribution to spatial learning is that the nucleus accumbens would impair acquisition of new spatial learning, while leaving performance of pre- viously learned spatial information intact. This prediction is based on the view that a special aspect of behavior to which the accumbens is sensitive is a change in sensory (spatial) perception, such as that which can occur during new learning. In contrast, ventromedial caudate-putamen inactivation should impair both the acquisition of new information and the expression of prior learning. During both acquisition and retention performance, animals must continually evaluate the effectiveness of the current response strategy. Both acquisition and retention performance depend on such an evaluation. Floresco, Seamans, and Phillips (1997) have provided some validation of the above predictions by showing that inactivation of the ventral subiculum to accumbens projection impaired performance on goal-directed navigation in novel situations.

Comparing the relative unit-behavioral correlates of individual or large populations of accumbens and caudate-putamen neurons recorded simultaneously during acquisition and retention performance should also reveal the nature of the interactions between these subareas of the striatum. Complementary to the predictions of the effects of reversible inactivation on behavior, it is predicted that accumbens and caudate-putamen units (either individually or as a neural population code) would show changes in their relationships to behavior during acquisition. Accumbens units might change because active new learning involves a continual change in, or updating of, environmental perceptions as new strategies are tested and become more efficient. Caudate-putamen units might change because inherent to learning itself is the continual evaluation of the consequences of current behavioral strategies. If the task demands change in a familiar environment, both caudate-putamen and accumbens units should be affected. If the task demands remain the same but animals are tested in different environments, one might observe greater changes in accumbens correlates, when compared with caudate-putamen correlates. In any of these test phases, it would be of interest to also determine whether there are learning-induced changes in the temporal correlation of discharge across the accumbens and the caudate-putamen. If such a correlation is found, it would further support the view that these two regions function together to achieve a common goal.

\section{REFERENCES}

Alexander, G. E., \& Crutcher, M. D. (1990). Neural representations of the target (goal) of visually guided arm movements in three motor areas of the monkey. Journal of Neurophysiology, 64, 164.

Annett, L. E., McGregor, A., \& RobBins, E. W. (1989). The effects of ibotenic acid lesions of the nucleus accumbens on spatial learning and extinction in the rat. Behavioural Brain Research, 31, 231-242.

Apicella, P., Legallet, E., \& Trouche, E. (1997). Responses of tonically discharging neurons in the monkey striatum to primary rewards delivered during different behavioral states. Experimental Brain Research, 116, 456-466.

Beckstead, R. M., Domesick, V. B., \& Nauta, W. J. H. (1979). Efferent connections of the substantia nigra and ventral tegmental area in the rat. Brain Research, 175, 191-217.

Burgess, N., Recce, M., \& O'KeEFE, J. (1994). A model of hippocampal function. Neural Networks, 7, 1065-1081. 
Butcher, L. L., \& WoOLF, N. J. (1984). Histochemical distribution of acetylcholinesterase in the central nervous system: Clues to the localization of cholinergic neurons. In A. Bjorklund, T. Hokfelt, \& M. J. Kuhar (Eds.), Handbook of chemical neuroanatomy (pp. 1-45). Amsterdam: Elsevier.

CHO, J., \& West, M. O. (1997). Distributions of single neurons related to body parts in the lateral striatum of the rat. Brain Research, $\mathbf{7 5 6}$, 241-246.

Colby, C. L., \& Duhamel, J. R. (1991). Heterogeneity of extrastriate visual areas and multiple parietal areas in the macaque monkey. $\mathrm{Neu}$ ropsychologia, 29, 517-537.

Colby, C. L., \& Duhamel, J. R. (1996). Spatial representations for action in parietal cortex. Cognitive Brain Research, 5, 105-115.

Colombo, P. J., Davis, H. P., \& VolPE, B. T. (1989). Allocentric spatial and tactile memory impairments in rats with dorsal caudate lesions are affected by preoperative behavioral training. Behavioral Neuroscience, 103, 1242-1250.

COOK, D., \& KESNER, R. P. (1988). Caudate nucleus and memory for egocentric localization. Behavioral \& Neural Biology, 49, 332-343.

Devan, B. D., \& WhITE, N. M. (1997). Dissociable mnemonic roles of discrete striatal territories: Comparison to the hippocampal system. Society for Neuroscience Abstracts, 23, 777

Duhamel, J. R., Colby, C. L., \& Goldberg, M. E. (1992). The updating of the representation of visual space in parietal cortex by intended eye movements. Science, 255, 90-92.

EicheNBAUM, H. (1996). Is the rodent hippocampus just for 'place'? Current Opinion in Neurobiology, 6, 187-195.

Everitt, B. J., Morris, K. A., O'Brien, A., \& Robins, T. W. (1991). The basolateral amygdala-ventral striatal system and conditioned place preference: Further evidence of limbic-striatal interactions underlying reward-related processes. Neuroscience, 42, 1-18.

Flaherty, A. W., \& Graybiel, A. M. (1993). Two input systems for body representations in the primate striatal matrix: Experimental evidence in the squirrel monkey. Journal of Neuroscience, 13, 1120.

Floresco, S. B., Seamans, J. K., \& Phillips, A. G. (1996a). Differential effects of lidocaine infusions into the ventral $\mathrm{CAl}$ /subiculum or the nucleus accumbens on the acquisition and retention of spatial information. Behavioural Brain Research, 81, 163-171

Floresco, S. B., Seamans, J. K., \& Phillips, A. G. (1996b). A selective role for dopamine in the nucleus accumbens of the rat in random foraging but not delayed spatial win-shift-based foraging. Behavioural Brain Research, 80, 161-168.

Floresco, S. B., Seamans, J. K., \& Phillips, A. G. (1997). Selective roles for hippocampal, prefrontal, and ventral striatal circuits in radial-arm maze tasks with or without a delay. Journal of Neuroscience, 17, 1880-1890.

Fogassi, L., Gallese, V., Pelligrino, G., Fadiga, L., Gentilucci, M., Lluppino, G., Matelli, M., Pedotti, A., \& Rizzolatti, G. (1992). Space coding by premotor cortex. Experimental Brain Research, 89 , 686-690.

FurTado, J. C. S., \& MAZUREK, M. F. (1996). Behavioral characterization of quinolinate-induced lesions of the medial striatum: Relevance foe Huntington's disease. Experimental Neurology, 138, 158-168.

Gal, G., Joel, D., Gusak, O., Feldon, J., \& Weiner, I. (1997). The effects of electrolytic lesion to the shell subterritory of the nucleus accumbens on delayed non-matching-to-sample and four-arm baited eight-arm radial-maze tasks. Behavioral Neuroscience, 111, 92-103.

Gardiner, T. W., \& KiTAI, S. T. (1992). Single-unit activity in the globus pallidus and neostriatum of the rat during performance of a trained head movement. Experimental Brain Research, 88, 517-530.

Gentilucci, M., Scandolara, C., Pigarev, I., \& Rizzolatti, G. (1983). Visual responses in the postarcuate cortex (area 6) of the monkey that are independent of eye position. Experimental Brain Research, 50, 464-468.

GeRFEN, C. R. (1992). The neostriatal mosaic: Multiple levels of compartmental organization in the basal ganglia. Annual Review of Neurscience, 15, 285-320.

Gross, C. G., \& Graziano, M. S. A. (1995). Multiple representations of space in the brain. Neuroscientist, 1, 43-50.

Heimer, L., Zahm, D. S., \& Alheid, G. F. (1995). Basal ganglia. In
G. Paxinos (Ed.), The rat nervous system (2nd ed., pp. 579-628). San Diego: Academic Press.

Hikosaka, O., Sakamoto, M., \& Usui, S. (1989). Functional properties of monkey caudate neurons: III. Activities related to expectation of target and reward. Joumal of Neurophysiology, 61, 814-832.

Houk, J. C. (1995). Information processing in modular circuits linking basal ganglia and cerebral cortex. In J. C. Houk, J. L. Davis, \& D. G. Beiser (Eds.), Models of information processing in the basal ganglia (pp. 3-10). Cambridge, MA: MIT Press.

Jongen-Relo, A. L., Groenewegen, H. J., \& Voorn, P. (1993). Evidence for a multi-compartmental histochemical organization of the nucleus accumbens in the rat. Journal of Comparative Neurology, 337, 267-276.

KaWAGOE, R., TAKIKaWA, Y., \& Hikosaka, O. (1998a). Expectation of reward modulates cognitive signals in the basal ganglia. Nature Neuroscience, 1, 411-416.

KAWAGOE, R., TAKIKaWA, Y., \& Hikosaka, O. (1998b). Monkey caudate neurons have desire field. Society for Neuroscience Abstract, 24, 1651.

Kawaguchi, Y., Wilson, C. J., \& Emson, P. C. (1990). Projection subtypes of rat neostriatal matrix cells as revealed by intracellular injection of biocytin. Journal of Neumscience, 10, 3421-3438.

Kelley, A. E., \& Domesick, V. B. (1982). The distribution of the projection from the hippocampal formation to the nucleus accumbens in the rat: An anterograde and retrograde horseradish peroxidase study. Neuroscience, 7, 615-630.

KeMP, J. M., \& Powell, T. P. S. (1970). The cortico-striate projection in the monkey. Brain, 93,525 .

KesNer, R. P., Bolland, B. L., \& DAKIs, M. (1993). Memory for spatial locations, motor responses, and objects: Triple dissociation among the hippocampus, caudate nucleus, and extrastriate cortex. Experimental Brain Research, 93, 462-470.

KIM, J. J., \& FANSELOW, M. S. (1992). Modality-specific retrograde amnesia of fear. Science, 256, 675-677.

KIMURA, M. (1990). Behaviorally contingent property of movementrelated activity of the primate putamen. Journal of Neurophysiology, 63, 1277.

Kitai, S. T., Preston, R. J., Bishop, G. A., \& Koscis, J. D. (1979). Striatal projection neurons: Morphological and electrophysiological studies. Advances in Neurology, 24, 45-51.

Knowlton, B. J., MANGELS, J. A., \& SQUiRE, L. R. (1996). A neostriatal habit learning system in humans. Science, 273, 1399-1402.

LAVoie, A. M., \& Mizumori, S. J. Y. (1994). Spatial-, movement, and reward-sensitive discharge by medial ventral striatum neurons of rats. Brain Research, 638, 157-168.

Maldonado-IrizarRy, C. S., \& Kelley, A. E. (1995). Excitatory amino acid receptors with nucleus accumbens subregions differentially mediate spatial learning in the rat. Behavioural Pharmacology, 6, 527-539.

McDonald, R. J., \& White, N. M. (1993). A triple dissociation of memory systems: Hippocampus, amygdala and dorsal striatum. Behavioral Neuroscience, 105, 3-22.

MCDonald, R. J., \& White, N. M. (1994). Parallel information processing in the water maze: Evidence for independent memory systems involving dorsal striatum and hippocampus. Behavioral \& Neural Biology, 61, 260-270.

MCGeORGE, A. J., \& FAULL, R. L. M. (1989). The organization of the projection from the cerebral cortex to the striatum in the rat. Neuroscience, 29, 503-537.

McNaughton, B. L., Barnes, C. A., Gerrard, J. L., Gothard, K. Jung, M. W., Knierim, J. J., Kudrimoti, H., QIN, Y., SkaGgs, W. E., Suster, M. S., \& WeAver, K. L. (1996). Deciphering the hippocampal polyglot: The hippocampus as a path integration system. Journal of Experimental Biology, 199, 173-185.

Merzenich, M. M., \& DeCharms, R. C. (1996). Neural representations, experience, and change. In R. Llinas \& P. S. Churchland (Eds.), The mind-brain continuum: Sensory processes (pp. 61-81). Cambridge, MA: MIT Press

Mitchell J. A., Channell, S., \& Hall, G. (1985). Responsereinforcer associations after caudate-putamen lesions in the rat: Spatial discrimination and overshadowing-potentiation effects in instrumental learning. Behavioral Neuroscience, 99, 1074-1088. 
Mrtchell, J. A., \& HaLl, G. (1988). Learning in rats with caudateputamen lesions: Unimpaired classical conditioning and beneficial effects of redundant stimulus cues on instrumental and spatial learning deficits. Behavioral Neuroscience, 102, 504-514.

MizUMORI, S. J. Y. (1994). Neural representations during spatial navigation. Current Directions in Psychological Science, 3, 125-129.

MizumoRI, S. J. Y., \& CoOPER, B. G. (1995). Spatial representations of dorsal caudate neurons of freely-behaving rats. Society for Neuroscience Abstracts, 21, 1929.

Mizumori, S. J. Y., Lavoie, A., \& Kalyani, A. (1996). Redistribution of spatial representation in the hippocampus of aged rats performing a spatial memory task. Behavioral Neuroscience, 110, 1006-1016.

Mizumori, S. J. Y., MCNaughton, B. L., BARnes, C. A., \& Fox, K. B. (1989). Preserved spatial coding in hippocampal CA1 pyramidal cells during reversible suppression of $\mathrm{CA} 3$ output: Evidence for pattern completion in hippocampus. Journal of Neuroscience, 9, 3915-3928.

Mizumori, S. J. Y., Ragozzino, K. E., \& CoOper, B. G. (1999). Dorsal striatal representation during adaptive navigation by rats. Manuscript submitted for publication.

Mizumori, S. J. Y., Ragozzino, K. E., Leutgeb, S., \& Cooper, B. G. (1998). Complementary roles of caudate and hippocampus during navigation: Evidence from parallel single unit recordings. Society for Neuroscience Abstracts, 24, 1911.

Mizumori, S. J. Y., UNick, K. E., \& COOPER, B. G. (1996). Dynamic reward and spatial codes of caudate nucleus neurons. Society for Neuroscience Abstracts, 22, 680.

Mogenson, G. J., \& YANG, C. R. (1991). The contribution of basal forebrain to limbic-motor integration and the mediation of motivation to action. Advances in Experimental Biology \& Medicine, 295, 267-290.

Morris, R. G. M., GarRud, P., RaWlins, J. N. P., \& O'KeEfe, J. (1982). Place navigation impaired in rats with hippocampal lesions. Nature, 197, 681-683.

Muller, R. U., Stead, M., \& PACH, J. (1996). The hippocampus as a cognitive graph. Journal of General Physiology, 107, 663-694.

O'KeEFE, J., \& Dostrovsky, L. (1971). The hippocampus as a spatial map: Preliminary evidence from unit activity in the freely-moving rat. Brain Research, 34, 171-175.

O'KEEFE, J., \& NADEL, L. (1978). The hippocampus as a cognitive map. London: Oxford University Press.

Olton, D. S., WALkER, J. A., \& GAGE, F. H. (1978). Hippocampal connections and spatial discrimination. Brain Research, 139, 295-308.

PaCKard, M. G., HirSh, R., \& WhITE, N. M. (1989). Differential effects of fornix and caudate nucleus lesion on two radial maze tasks: Evidence for multiple memory systems. Journal of Neuroscience, 9 , 1465-1472.

PACKARD, M. G., \& MCGAUGH, J. L. (1996). Inactivation of hippocampus or caudate nucleus with lidocaine differentially affects expression of place and response learning. Neurobiology of Learning \& Memory, 65, 66-72.

Ploeger, G. E., Spruijt, B. M., \& CoOls, A. R. (1994). Spatial localization in the Morris water maze in rats: Acquisition is affected by intra-accumbens injections of the dopaminergic antagonist haloperidol. Behavioral Neuroscience, 108, 927-934.

Poucet, B., \& Benhamou, S. (1997). The neuropsychology of spatial cognition in the rat. Critical Reviews in Neurobiology, 11, 101-120.

Ragozzino, K. E., \& MizUMORI, S. J. Y. (1998). The effects of spatial memory acquisition on caudate and hippocampal spatial representations. Society for Neuroscience Abstracts, 24, 1911.

Redish, A. D., \& Touretzky, D. S. (1997). Cognitive maps beyond hippocampus. Hippocampus, 7, 15-35.

Robins, T. W., \& EveriTT, B. J. (1996). Neurobehavioural mecha- nisms of reward and motivation. Current Opinion in Neurobiology, 6, 228-236.

RoLLs, E. T. (1994). Neurophysiology and cognitive functions of the striatum. Reviews in Neurology, 150, 648-660.

Rolls, E. T., Thorpe, S. J., \& Maddison, S. P. (1983). Responses of striatal neurons in the behaving monkey: I. Head of the caudate nucleus. Behavioural Brain Research, 7, 179-210.

Schultz, W., Apicella, P., Romo, R., \& Scarnati, E. (1995). Contextdependent activity in the primate striatum reflecting past and future behavioral events. In J. C. Houk, J. L. Davis, \& D. G. Beiser (Eds.), Models of information processing in the basal ganglia (pp. 11-27). Cambridge, MA: MIT Press.

Schultz, W., \& Romo, R. (1992). Role of primate basal ganglia and frontal cortex in the internal generation of movements: Comparison with instruction-induced preparatory activity in striatal neurons. $E x$ perimental Brain Research, 91, 363-384.

SCOVILLE, W. B., \& MILNER, B. (1957). Loss of recent memory after bilateral hippocampal lesions. Journal of Neurology. Neurosurgery \& Psychiatry, 20, 11-21.

Seamans, J. K., \& Philips, A. G. (1994). Selective memory impairments produced by transient lidocaine-induced lesions of the nucleus accumbens in rats. Behavioral Neuroscience, 108, 456-468.

Sharp, P. E., Blair, H. T., \& Brown, M. (1996). Neural network modeling of the hippocampal formation spatial signals and their possible role in navigation: A modular approach. Hippocampus, 6, 720-734.

STERN, E. A., JAEGER, D., \& WILSON, C. J. (1998). Membrane potential synchrony of simultaneously recorded striatal spiny neurons in vivo. Nature, 394, 475-478.

Sutherland, R. J., \& Rodriguez, A. J. (1989). The role of the fornix fimbria and some related subcortical structures in place learning and memory. Behavioural Brain Research, 32, 265-277.

Taube, J. S., Goodridge, J. P., Golob, E. J., Dudchenko, P. A., \& Stackman, R. W. (1996). Processing the head direction cell signal: A review and commentary. Brain Research Bulletin, 40, 477-486.

Weiner, I., Gal, G., Rawlins, J. N. P., \& Feldon, J. (1996). Differential involvement of the shell and core subterritories of the nucleus accumbens in latent inhibition and amphetamine-induced activity. $B e-$ havioural Brain Research, 81, 123-133.

Whishaw, I. Q., Mitrleman, G., Bunch, S. T., \& Dunnett, S. B. (1987). Impairments in the acquisition, retention and selection of spatial navigation strategies after medial caudate-putamen lesions in rats. Behavioural Brain Research, 24, 125-138.

WIENER, S. (1993). Spatial and behavioral correlates of striatal neurons in rats performing a self-initiated navigation task. Journal of Neuroscience, 13, 3802-3817.

WIENER, S. (1996). Spatial, behavioral and sensory correlates of hippocampal CA1 complex spike cell activity: Implications for information processing functions. Progress in Neurobiology, 49, 335-361.

WILsON, C. J. (1995). The contribution of cortical neurons to the firing pattern of striatal spiny neurons. In J. C. Houk, J. L. Davis, \& D. G. Beiser (Eds.), Models of information processing in the basal ganglia (pp. 29-50). Cambridge, MA: MIT Press.

Wise, S. P., Murray, E. A., \& Gerfen, C. R. (1996). The frontal cortexbasal ganglia system in primates. Critical Reviews in Neurobiology, 10, 317-356.

Zola-Morgan, S. M., \& Squire, L. R. (1990). The primate hippocampal formation: Evidence for a time-limited role in memory storage. Science, 250, 288-290.

(Manuscript received September 23, 1998; revision accepted for publication December 21, 1998.) 